\title{
TRAJETÓRIAS ESCOLARES: A PEDAGOGIA DA UNIARA COMO POSSIBILIDADE DE ASCENSÃO AOS NÍVEIS SUPERIORES E DE PROFISSIONALIZAÇÃO DE ALUNOS DAS CAMADAS POPULARES
}

\author{
Fábio Tadeu REINA* \\ Luci Regina MUZZETI ${ }^{* *}$ \\ Denise Maria MARGONARI**
}

RESUMO: Este artigo pretendeu apontar e analisar os itinerários de vida escolar de alunos das camadas populares e como atingiram o nível superior de escolarização, os porquês escolheram fazer a graduação em pedagogia e o que pensam da profissão de pedagogo. Para isto foram analisados depoimentos e relatos de nove alunas do Curso de pedagogia da UNIARA concluintes em 2012. Concluiu-se que a UNIARA, por meio de suas estratégias e incentivos de isenção de taxas e a maneira como o curso é estruturado e como os professores do curso de Pedagogia desenvolvem seu trabalho docente, tornou-se uma possibilidade real para que esses alunos alcançassem o tão sonhado diploma de nível superior e pudessem ter condições de tornarem-se professores e ingressarem no mercado de trabalho.

PALAVRAS-CHAVE: Itinerários. Camadas populares. Pedagogia.

\footnotetext{
* UNESP - Universidade Estadual Paulista. Faculdade de Ciências e Letras - PósGraduação em Educação Sexual. Araraquara - SP - Brasil. 14800-000 - ftreina@ig.com.br. ** UNESP - Universidade Estadual Paulista. Faculdade de Ciências e Letras Departamento de Didática. Araraquara - SP - Brasil. 14800-000 - lucirm@fclar.unesp.br. *** UNESP - Universidade Estadual Paulista. Faculdade de Ciências e Letras Departamento de Didática. Araraquara - SP - Brasil. 14800-000 - denisemargonari@fclar. unesp.br.
} 


\section{Introduçáo}

Verificou-se nos últimos anos que estudar cientificamente no campo educacional o sucesso e fracasso escolar dos alunos provenientes das camadas populares atingiu uma dimensão além da esfera nacional. Estudos internacionais como os de Lahire (1997) e os nacionais como os de Portes (2003), Viana (2007), dentre outros, intencionaram-se a apontar os mecanismos e as estratégias que de certa forma explicariam a longevidade escolar desse alunato. Nesta direção, este artigo, pretende apontar e analisar as condiçóes que levaram esses alunos a atingirem esse nível de escolarizaçáo, a escolha pela graduação em pedagogia e por último verificar a desenvoltura deles durante o curso e o que pensam da profissão de pedagogo.

Estudos desta natureza são de extrema importância porque faz com que a instituição possa fomentar cada vez mais política de acesso e permanência desses alunos até a conclusão do curso, já que se trata de uma carreira extremamente desvalorizada e desprestigiada socialmente.

\section{O Centro Universitário de Araraquara - UNIARA}

Com a criação da Associação São Bento de Ensino - ASBE, em 1968, foi inaugurada uma etapa que transformou o ensino superior de Araraquara e regiáo. Naquele ano, o MEC avalizou a criação da Faculdade de Ciências Econômicas e Administrativas de Araraquara, com os cursos de Administração e Ciências Econômicas.

Pouco depois, em 1970, foi autorizada a Faculdade de Direito de Araraquara e, em 1971, a Faculdade de Educação de Araraquara (que em 1974 se transformaria na Faculdade de Educação e Estudos Sociais de Araraquara). Diante dessa expansão, foi fundada, em 1972, a Federação das Faculdades Isoladas de Araraquara - Fefiara, que passou a congregar as faculdades então existentes. Em 1997, a Instituição conseguiu o seu credenciamento como Centro Universitário, ganhando autonomia para novas perspectivas de crescimento. Nascia a Uniara.

Hoje, a Uniara possui mais de 600 funcionários e mais de sete mil alunos de graduação nos seguintes cursos: Agronomia, Administração, Arquitetura e Urbanismo, Biologia, Biomedicina, 
Design de Moda, Design Digital, Direito, Economia, Educação Física, Enfermagem, Engenharia Bioenergética, Engenharia Civil, Engenharia de Computação, Engenharia de Produção, Engenharia Elétrica, Engenharia Mecatrônica, Estética e Cosmetologia, Farmácia, Fisioterapia, Jornalismo, Medicina, Nutrição, Odontologia, Pedagogia, Psicologia, Publicidade e Propaganda, Sistemas de Informação, Terapia Ocupacional.

\section{$O$ curso de pedagogia}

O curso de Pedagogia da Uniara tem a intenção de formar professores capazes de responder aos desafios impostos pelo mundo moderno. Desenvolver competências profissionais, como metodologias pautadas na articulação teoria-prática, resolução de situações-problema e reflexôes individual e compartilhada da atuação profissional, colocando o futuro professor em contato com a realidade em que irá atuar e com as questôes concretas da profissão, desde o início do curso. Tem corpo docente formado por mestres e doutores, com experiência na Educação Infantil e nas séries iniciais do Ensino Fundamental. Seu quadro curricular distribui disciplinas de formação básica, de atuação multidisciplinar, de formação específica e de prática de ensino e estágio supervisionado.

Os programas de bolsa de estudos, como o Unibolsa, têm por objetivo estender o ensino de excelência ao maior número possível de pessoas, oferecendo quatro modalidades: bolsa auxílio, bolsa especial, bolsa convênio e bolsa fidelidade. A Instituição ainda é parceira do governo no Programa Universidade para Todos - PROUNI e no Programa de Financiamento Estudantil - Fies.

Diante do exposto, o centro Universitário de Araraquara (UNIARA) pode cobrar mensalidades bem inferiores às das outras instituiçôes de ensino particular, atraindo alunos pertencentes às camadas populares, vindos de cidades próximas a Araraquara, os quais passam a ter também a chance de cursar o ensino superior. A UNIARA remunera seus professores melhor que várias faculdades situadas nesta regiáo do Estado de Sáo Paulo, o que atrai profissionais com uma boa formação acadêmica, sendo a maioria do seu corpo docente é composta por mestres e doutores. 
Com tudo isto, foi definido o objeto deste estudo e realizada uma pesquisa em que se procurou analisar a trajetória escolar, pessoal, acadêmica e as expectativas com a profissão de pedagogo, vivida por um grupo de nove alunas concluintes do curso de Pedagogia da UNIARA no ano de 2012, com o objetivo principal de investigar como alcançaram o táo sonhado diploma do ensino superior.

Considerando as características específicas do objeto de estudo, optou-se por realizar uma pesquisa qualitativa, utilizando-se a abordagem biográfica. Foi observado por meio de memoriais acadêmicos do mencionado curso, exigidos como uma das modalidades de trabalho final, que os itinerários escolares das alunas foram, de maneira geral, pautados pela condiçáo material de existência das famílias e que houve uma mobilização intensa por parte delas e de seus membros para que obtivessem longevidade escolar, uma vez que a maioria é proveniente das camadas populares. Outro fato proveniente das leituras dos memoriais foi a mudança visível e gradativa operada em grande parte das alunas ao longo dos períodos cursados, em aspectos como: maneira de pensar, valores, gostos, uso da língua, e mesmo na maneira de vestir-se e de comportar-se.

Optamos por seguir na reconstrução das histórias de vida das futuras pedagogas. Foi considerado também o pertencimento social e de gênero dos sujeitos da pesquisa por se considerar que uma pesquisa sobre docentes que náo leva em conta tais pertencimentos acaba por produzir uma visão genérica.

\section{Itinerário escolar: a busca do diploma de nível superior, a pedagogia da UNIARA como possibilidade real}

Ao analisar os memoriais das alunas concluintes do curso de pedagogia da UNIARA do ano de 2012, pudemos observar uma regularidade histórica na trajetória de vida escolar de quase todas elas. Conflitos existenciais quando do momento de entrada na escola, como relata três delas, dizendo que choravam demais, muitas vezes as mães precisavam ficar um período do dia na escola junto, até o momento, onde este conflito ameniza-se e aí a escola, segundo seus depoimentos, passa a ser um lugar gostoso, alegre, que dá vontade de retornar logo.

$\mathrm{Na}$ situação acima observamos que a presença da família, mas particularmente da mãe acompanhando todo este processo é o ponto 
chave sobre o qual gostaríamos de salientar neste instante como fator determinante na mudança de comportamento de seus filhos, dando-lhes a confiança necessária para vencerem esta etapa tão dolorosa de suas vidas, segundo constatado nos depoimentos.

Mas além desta condição, outro momento, e este sim merece um destaque no nosso estudo, é o fato de que todas elas dizerem que as professoras nesta fase da escolarização (Educação infantil e ensino fundamental I) eram muito competentes, centradas nas suas obrigaçóes docentes, trabalhavam com motivação e entusiasmo.

Consideravam, ainda, de suma importância para suas formaçôes e prosseguimento nos níveis seguintes da escolarização básica e relatam no memorial, hoje muito tempo depois e concluintes de um curso que as habilita a trabalhar no magistério que foram estes exemplos que gostariam de seguir como futuras professoras.

Antes de chegarmos à realidade acima, retomamos suas trajetórias de vida escolar, quando estavam para concluir o ensino médio, porque neste momento de suas vidas, observamos pelos depoimentos que o conflito da entrada na escola, agora se faz presente de outra forma, pois a saída do ensino médio as leva a ter que escolher entre entrar no mercado de trabalho ou seguir nos níveis superiores.

Ao optarem pelo prosseguimento nos níveis superiores, verificamos pela análise dos depoimentos que novamente aquele conflito da entrada na escola, volta a estabelecer-se neste momento de suas vidas. A pergunta que todas fizeram a si mesmas, o que buscar como carreira profissional?

Pudemos observar que as respostas na sua maioria foram semelhantes, ou seja, pensavam em escolher várias carreiras profissionais, menos a de ser professora, embora uma apenas das nove escolhesse a Pedagogia logo de cara. Mas esta condição vem alicerçada pela formação de parentes próximos, três primas e uma irmã são professoras e fizeram pedagogia e a incentivava a seguir o mesmo caminho.

As demais depoentes objetivavam como primeira opçáo odontologia, fisioterapia, terapia ocupacional, turismo, dentre outras carreiras, mas não puderam alcançar estes objetivos, pois as condições financeiras, culturais e sociais não as possibilitavam a prestar o vestibular para estas carreiras, além deste fato, a família também não estimulava este sonho e até colocava obstáculos a tais escolhas. 
Segundo Bourdieu (2003), neste caso, a concordância das expectativas com as probabilidades, das antecipaçóes com as realizaçóes, está no principio dessa espécie de realismo, enquanto sentido da realidade e senso das realidades que faz com que, para além dos sonhos e das revoltas, cada um tenda a viver de acordo com a sua condição e tornar-se inconscientemente cúmplice dos processos que tendem a realizar o provável.

E o provável nestes casos, foi prestar vestibular para Pedagogia, primeiro porque se tratava de um curso com muitas vagas e historicamente nem todas preenchidas pelos candidatos, portanto deduziu-se que a aprovação seria eminente. Segundo que o valor das mensalidades do curso é o menor de todos os outros cursos elencados por elas. Terceiro que além de tudo isto, a UNIARA mantêm um programa de bolsas que facilita a manutenção dessas alunas no prosseguimento do curso, chegando a concluí-lo, recebendo o táo sonhado diploma de nível superior.

E, por fim e a nosso ver, o mais importante de todos os fatores acima, é que a família neste caso incentivava a decisão tomada de prestar vestibular para pedagogia e serem futuras professoras. Mesmo com todo desprestígio e desvalorização da carreira docente por parte da sociedade.

Ao ingressarem no curso, pudemos constatar pelos relatos que todas elas reestruturavam seus comportamentos, muito em função novamente do incentivo e atuação de vários professores. Segundo seus depoimentos são professores que inovam nas aulas, conseguem prender a atenção dos alunos e têm comprometimento com a profissão.

Além dessas consideraçóes, ainda para reestruturar seu capital cultural que segundo Bourdieu (2003), agentes sociais provenientes de fraçóes de classe populares, apresentam um capital cultural reduzido, a UNIARA através do curso de pedagogia organizava eventos, palestras, semana da pedagogia com minicursos, como por exemplo, de jogos, brincadeiras na educação infantil por meio da construção de materiais de sucata, viagens educacionais, como por exemplo, o museu da língua portuguesa.

Outro momento no curso que apontava ser de extrema importância para a consolidação da formação docente foram os estágios realizados em instituiçôes de ensino. Diziam que nos estágios puderam conhecer as diferentes práticas pedagógicas, mostrar a situação real da 
educação escolar nos seus níveis de ensino e com isso possibilitavam interagir aperfeiçoando novos conhecimentos e aproximando a teoria da prática.

E por fim, as amizades conquistadas durante o curso não só dos colegas de turma, mas de todos os professores dos quais tiveram aula, também foram de suma importância para suas formaçóes, pois proporcionavam novas aprendizagens e incentivo na continuidade e conclusão do curso.

E, ao serem professoras, todas elas tinham consciência de que ser professor é ter um papel muito importante dentro da sala de aula, ajudando o aluno a interpretar as informaçóes que recebem a todo o momento, precisa estar capacitado para saber aprender a aprender, saber agir em sala de aula, transformando todas essas informaçóes que os alunos trazem em uma aprendizagem para todos e com sabedoria.

\title{
Consideraçóes finais
}

Concluiu-se que a UNIARA por meio de suas estratégias e incentivos de isenção de taxas e a maneira como o curso é estruturado e como os professores desenvolvem seu trabalho docente, tornou-se uma possibilidade real para que alunos das camadas populares pudessem alcançar o tão sonhado diploma de nível superior e pudessem ter condiçóes de tornarem-se professoras e ingressarem no mercado de trabalho.

\section{SCHOOL PATHS: UNIARA PEDAGOGY AS THE POSSIBILITY OF RISING TO HIGHER LEVELS AND STUDENT PROFESSIONAL}

\begin{abstract}
This paper aims to point out and analyze the routes of school life for students from lower classes and how to reach the top level of schooling, the whys chose to do a degree in pedagogy and after that, check the resourcefulness of them during the course and what they think of the profession pedagogue. Were analyzed for this testimony and reports nine students Course pedagogy UNIARA graduating in 2012. It was concluded that the UNIARA through their strategies and incentive fee waivers and the way the course is structured and how teachers develop
\end{abstract}


their teaching, became a real possibility for them to reach the dream college degree and might be able to become teachers and entering the labor market.

KEYWORDS: Routes. Lower classes. Pedagogy.

\section{REFERÊNCIAS}

BOURDIEU, P. A economia das trocas simbólicas. 5.ed. São Paulo: Perspectiva, 2003.

LAHIRE, B. Sucesso escolar em meios populares: as razões do improvável. São Paulo: Ática, 1997.

PORTES, E. A. Trajetórias escolares e vida acadêmica do estudante pobre da UFMG: um estudo a partir de cinco casos. 267f. 2003. Tese (Doutorado em Educação) - Universidade Federal de Minas Gerais, Belo Horizonte, 2003.

VIANA, M. J. B. Longevidade escolar em famílias populares: algumas condiçôes de possibilidade. Goiânia: Ed. da UCG, 2007. 